\title{
Clinical manifestation and diagnostic process of celiac disease in Poland - comparison of pediatric and adult patients in ret-
} rospective study

Emilia Majsiak1,2,", Magdalena Choina ${ }^{2}$, Alastair M. Gray ${ }^{3}$, Mariusz Wysokiński ${ }^{4}$, Bożena Cukrowska ${ }^{5}$

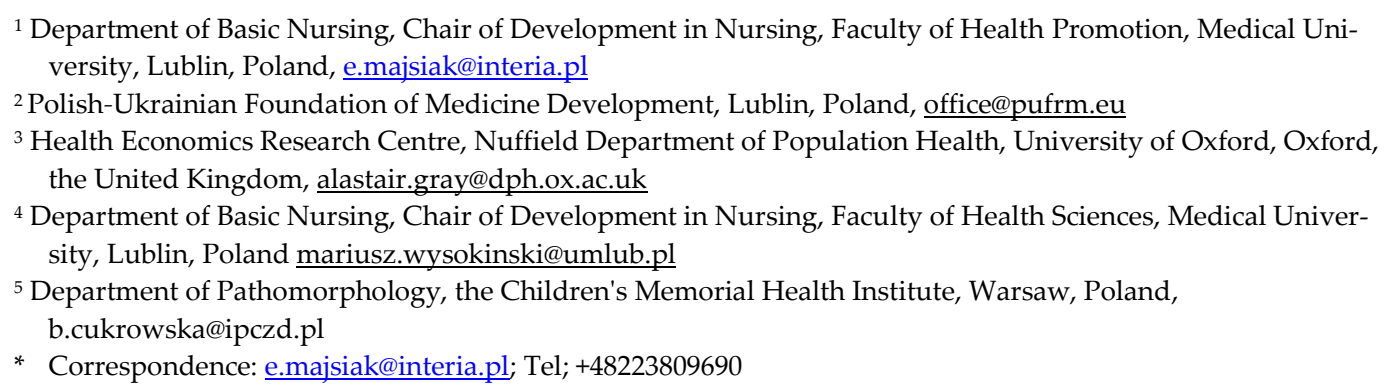

\begin{abstract}
The diagnosis of celiac disease (CD) may be delayed due to non-specific clinical symptoms. The aim of the study was to evaluate the clinical manifestation and diagnostic process of CD in Polish children and adults. Methods: The members of the Polish Coeliac Society $(n=2500)$ were asked to complete a questionnaire on socio-demographic factors, clinical and diagnostic aspects of $\mathrm{CD}$. The analysis was based on 796 responses from patients with confirmed CD diagnosis, and included $224(28.1 \%)$ children and $572(71.9 \%)$ adults. Results: The mean duration of symptoms prior to $C D$ diagnosis in children was significantly shorter than in adults $(p<0.001)$, and amounted to 3.1 and 9 years respectively. The most frequent symptoms before $\mathrm{CD}$ diagnosis were abdominal pain and bloating in children (70.4\%), and chronic fatigue in adults (74.5\%). Although almost all CD patients claimed to strictly avoid gluten after $\mathrm{CD}$ diagnosis, symptoms were still present in the majority of these respondents. No comorbid diseases were reported by $29.8 \%$ of children and by $11.7 \%$ of adults $(\mathrm{p}<0.001)$. Conclusions: The results indicate that CD diagnosis is delayed in Poland, especially in adults, and clinicians should be aware of the diversity in CD presentation.
\end{abstract}

Keywords: Celiac disease, diagnostic process, gluten free diet, delayed diagnosis

\section{Introduction}

Celiac disease (CD) is regarded as one of the most common autoimmune disorders of the alimentary tract with a global prevalence based on serologic test results of $1.4 \%$, with evidence of increasing prevalence across recent decades [1]. Research indicates that the incidence of $\mathrm{CD}$ is highest in women and children [2].

The "classical" type of $\mathrm{CD}$, which occurs mainly in younger paediatric patients, is characterized by chronic diarrhoea and malabsorptive features [3]. In the non-classical $\mathrm{CD}$, which is more and more often observed in both children and adults, symptoms from outside the gastrointestinal tract, such as short stature, anaemia, decreased bone density, skin changes, chronic fatigue, headaches and depression predominate [4]. The varied clinical presentation of the disease may contribute to a significant delay or even failure to diagnose $\mathrm{CD}$ [5]. Early detection of $\mathrm{CD}$ and the implementation of gluten-free diet (GFD) may improve the quality of life of $\mathrm{CD}$ patients and reduce the costs of diagnostic processes and subsequent therapy [6]. Undiagnosed CD could result in serious complications, including oncological diseases and infertility [7]. A delay in CD diagnosis may affect not only somatic, but also psychological well-being. Symptomatic CD patients who 
are undiagnosed are likely to take medicines or use health care services excessively. An increase in days of sickness and doctor visits as well as in intake of antidepressants and drugs for dyspepsia has been observed among Finnish patients with delayed CD diagnosis $[4,8]$.

In our recent study, we reported that the time from first symptoms to diagnosis of $\mathrm{CD}$ in Poland lasted 7.3 years on average. Although long, this was significantly shorter ( $p$ $<0.001$ ) than the comparable CD diagnostic delay in the United Kingdom of 13.2 years [9]. This difference might be partly explained by the fact that there were more children in the Polish study group than in the British study group (28.1\% and $12.4 \%$, respectively). As children constituted almost one third of Polish study group, the duration of symptoms prior to CD diagnosis in Polish children and adults should be verified. Thus, the aim of the current study was to identify and compare differences in the diagnostic process of $\mathrm{CD}$ among paediatric and adult $\mathrm{CD}$ patients.

\section{Materials and Methods}

\subsection{Study design}

The study was performed among members of Polish Coeliac Society (www.celiakia.pl). This society includes patients with diagnosed CD and those who adopted a GFD on their own. Two and a half thousand members of the society were sent a letter with information on the planned study and a request to complete the attached questionnaire. Of this number, 969 (38.76\%) surveyees returned the questionnaire. Patients who had adopted a GFD individually without a CD diagnosis $(n=173)$ were excluded from the study, leaving 796 questionnaires included in the analysis. Parents or guardians were asked to complete the questionnaire on behalf of children (under the age of 18). The study was conducted with the consent of the Bioethics Committee of the Children's Memorial Health Institute (No. 48 /KBE/2017).

\subsection{Questionnaires}

The detailed description of the questionnaire was presented in our recently published paper [9]. The questionnaire was based on the original questionnaire "The Impact of Coeliac Disease on Your Life: A Survey of Your Views" developed by Gray and Papanicolas with the consent of the authors [10]. Respondents were asked to answer questions about socio-demographic factors, diagnostic and clinical aspects and CD-related costs they had incurred. The questionnaire distributed among members of Polish Coeliac Society was modified compared to the original British questionnaire. In particular, a question concerning the decision to start GFD was added, to allow respondents who had adopted a GFD without a CD diagnosis to be excluded. Surveyees who indicated that a GFD had been adopted after a CD diagnosis were then asked about the method in which the diagnosis was made: blood test (without specification of the serological tests), duodenal biopsy, genetic examination or any other type of examination, which they were asked to specify. Surveyees were also asked to indicate the specialization of the clinician who had made the CD diagnosis.

\subsection{Statistical analysis}

Statistical analysis was performed using Statistica 10 (StatSoft Poland). Two variables were compared using Wilcoxon's test, while three variables were compared using the Kruskal-Wallis test. Due to the fact that the Kruskal-Wallis test indicates only the presence of statistically significant difference, Bonferroni's test was performed for further analysis. Chi-squared tests were used to define statistically significant correlations between qualitative variables. To test the statistical significance of differences by gender, the Fisher exact test was used. To measure correlation between variables, Spearman's rank correlation coefficient was used. Continuous variables were summarized using mean values, while variability around mean values was reported in terms of standard 
deviations (SD). The precision around mean values was described with $95 \%$ confidence intervals (CI). A p-value $<0.05$ was considered as statistically significant.

\section{Results}

\subsection{Characteristics of paediatric and adult patients}

A total of 796 questionnaires were returned, of which 224 (28.14\%) were children and $572(71.86 \%)$ adults (Table 1$)$. A majority of respondents were female in both groups $-58.5 \%(131 / 224)$ among children, and $89.3 \%(511 / 572)$ among adults. The average age of patients at CD diagnosis was 6.8 years in the paediatric group and 34.3 years in the adult group, while mean age at survey was 9.7 years (range 2 to 18) and 37.2 years (range $>18$ to 80 ) in children and adults, respectively. The longest reported duration of diagnosed CD was 53 years.

Table 1. Characteristics of the study group.

\begin{tabular}{|c|c|c|c|}
\hline Variables & All patients & Children & Adults \\
\hline $\begin{array}{c}\text { No. of included question- } \\
\text { naires }\end{array}$ & 796 & $224(28.1 \%)$ & $572(71.9 \%)$ \\
\hline $\begin{array}{l}\text { Sex }- \text { No. } \\
(\%)\end{array}$ & $\begin{array}{l}642(80.7 \%) \\
127(19.3 \%)\end{array}$ & $\begin{array}{c}131(58.5 \%) \\
93(41.5 \%)\end{array}$ & $\begin{array}{l}511(89.3 \%) \\
61(10.7 \%)^{1}\end{array}$ \\
\hline $\begin{array}{l}\text { Average age at survey in } \\
\text { years - Mean (SD) }\end{array}$ & $29.4(16.0)$ & $9.7(3.8)$ & 37.2 (11.7) \\
\hline $\begin{array}{c}\text { Average age at diagnosis in } \\
\text { years - Mean (SD) }\end{array}$ & $24.1(15.9)$ & $6.8(4.2)$ & 34.3 (10.6) \\
\hline
\end{tabular}

${ }_{1}$ There was a statistically significantly higher proportion of females in adults compared with pediatric patients $(\mathrm{p}=0.0001)$. Fisher exact test was used for statistical analysis. $\mathrm{SD}=$ standard deviation.

\subsection{Clinical symptoms}

Respondents were asked to report the symptoms they had experienced and their mean duration before CD diagnosis (Table 2). ). Abdominal pain/bloating (69.3\%), chronic fatigue $(61 \%)$, flatulence $(58.4 \%)$, anaemia $(55.2 \%)$ and diarrhoea $(54.5 \%)$ were the most common symptoms in the whole analysed group, regardless of the age. Adults stated that the most frequent symptoms were: chronic fatigue $(74.5 \%)$, abdominal pain/bloating $(68.7 \%)$, anaemia $(63.7 \%)$ and flatulence $(62.4 \%)$. The most common symptoms among children were: abdominal pain/bloating (70.4\%), flatulence $(51.7 \%)$, diarrhoea $(48.6 \%)$ and anaemia $(40.8 \%)$. The vast majority of symptoms (excluding abdominal pain/bloating, skin rash and weight loss) were significantly more common in adults than in children prior to CD diagnosis: diarrhoea $(p=0.011)$, constipation $(p=$ $0.008)$, osteoporosis $(p=0.005)$, flatulence $(p=0.003)$, chronic fatigue, headaches, mouth ulcers, anaemia and depression $(p<0.001)$. No symptoms prior to CD diagnosis were declared by $4 \%$ of children and by $3 \%$ of adults (Table 2 ). 
Table 2. Frequency and mean duration of symptoms prior to CD diagnosis in pediatric and adult patients.

\begin{tabular}{|c|c|c|c|c|c|c|c|c|}
\hline \multirow[b]{2}{*}{ Symptoms } & \multicolumn{4}{|c|}{$\begin{array}{c}\text { Number and percentage of patients reporting each } \\
\text { symptom }\end{array}$} & \multicolumn{4}{|c|}{ Mean duration in years after $\mathrm{CD}$ diagnosis } \\
\hline & $\begin{array}{c}\text { All } \\
\text { patients } \\
(\mathrm{n}=796)\end{array}$ & $\begin{array}{l}\text { Children } \\
(\mathrm{n}=294)^{1}\end{array}$ & $\begin{array}{l}\text { Adults } \\
(\mathrm{n}=502)^{1}\end{array}$ & $\mathrm{p}$ & $\begin{array}{c}\text { All } \\
\text { patients } \\
(n=796)\end{array}$ & $\begin{array}{l}\text { Children } \\
(\mathrm{n}=294)^{1}\end{array}$ & $\begin{array}{l}\text { Adults } \\
(\mathrm{n}=502)^{1}\end{array}$ & $\mathbf{p}$ \\
\hline Flatulence & $\begin{array}{c}465 \\
(58.4 \%)\end{array}$ & $\begin{array}{c}152 \\
(51.7 \%)\end{array}$ & $\begin{array}{c}313 \\
(62.4 \%)\end{array}$ & 0.003 & 8.1 & 3.6 & 10.3 & $<0.001$ \\
\hline $\begin{array}{c}\text { Abdominal } \\
\text { pain/Bloating }\end{array}$ & $\begin{array}{c}552 \\
(69.3 \%)\end{array}$ & $\begin{array}{c}207 \\
(70.4 \%)\end{array}$ & $\begin{array}{c}345 \\
(68.7 \%)\end{array}$ & 0.619 & 7.1 & 3.1 & 9.4 & $<0.001$ \\
\hline Chronic fatigue & $\begin{array}{c}486 \\
(61.0 \%)\end{array}$ & $\begin{array}{c}112 \\
(38.1 \%)\end{array}$ & $\begin{array}{c}374 \\
(74.5 \%)\end{array}$ & $<0.001$ & 6.3 & 2.9 & 7.3 & $<0.001$ \\
\hline Anaemia & $\begin{array}{c}440 \\
(55.2 \%)\end{array}$ & $\begin{array}{c}120 \\
(40.8 \%)\end{array}$ & $\begin{array}{c}320 \\
(63.7 \%)\end{array}$ & $<0.001$ & 9.2 & 2.8 & 11.6 & $<0.001$ \\
\hline Diarrhoea & $\begin{array}{c}434 \\
(54.5 \%)\end{array}$ & $\begin{array}{c}143 \\
(48.6 \%)\end{array}$ & $\begin{array}{c}291 \\
(58.0 \%)\end{array}$ & 0.011 & 4.7 & 2.4 & 5.8 & 0.001 \\
\hline Headache & $\begin{array}{c}350 \\
(43.9 \%)\end{array}$ & $\begin{array}{c}80 \\
(27.2 \%)\end{array}$ & $\begin{array}{c}270 \\
(53.8 \%)\end{array}$ & $<0.001$ & 8.6 & 3.1 & 10.3 & $<0.001$ \\
\hline Weight loss & $\begin{array}{c}337 \\
(42.3 \%)\end{array}$ & $\begin{array}{c}118 \\
(40.1 \%)\end{array}$ & $\begin{array}{c}219 \\
(43.6 \%)\end{array}$ & $<0.001$ & 5.2 & 3.0 & 6.4 & 0.014 \\
\hline Skin rash & $\begin{array}{c}289 \\
(36.3 \%)\end{array}$ & $\begin{array}{c}105 \\
(35.7 \%)\end{array}$ & $\begin{array}{c}184 \\
(36.7 \%)\end{array}$ & 0.790 & 7.4 & 3.9 & 9.3 & $<0.001$ \\
\hline Joint pains & $\begin{array}{c}269 \\
(33.7 \%)\end{array}$ & $\begin{array}{c}60 \\
(20.4 \%)\end{array}$ & $\begin{array}{c}209 \\
(41.6 \%)\end{array}$ & $<0.001$ & 7.6 & 3.7 & 8.8 & $<0.001$ \\
\hline Constipation & $\begin{array}{c}271 \\
(34.0 \%)\end{array}$ & $\begin{array}{c}83 \\
(28.2 \%)\end{array}$ & $\begin{array}{c}188 \\
(37.5 \%)\end{array}$ & 0.008 & 8.5 & 2.7 & 11.1 & $<0.001$ \\
\hline Mouth ulcer & $\begin{array}{c}256 \\
(32.1 \%)\end{array}$ & $\begin{array}{c}58 \\
(19.7 \%)\end{array}$ & $\begin{array}{c}198 \\
(39.4 \%)\end{array}$ & $<0.001$ & 7.2 & 2.8 & 8.5 & $<0.001$ \\
\hline Depression & $\begin{array}{c}145 \\
(18.2 \%)\end{array}$ & $\begin{array}{c}17 \\
(5.8 \%)\end{array}$ & $\begin{array}{c}128 \\
(25.5 \%)\end{array}$ & $<0.001$ & 5.8 & 4.1 & 6.0 & 0.298 \\
\hline Ataxia & $\begin{array}{c}58 \\
(7.2 \%)\end{array}$ & $\begin{array}{c}21 \\
(7.1 \%)\end{array}$ & $\begin{array}{c}37 \\
(7.4 \%)\end{array}$ & 0.905 & 5.6 & 2.9 & 7.1 & 0.465 \\
\hline Osteoporosis & $\begin{array}{c}53 \\
(6.6 \%)\end{array}$ & $\begin{array}{c}10 \\
(3.4 \%)\end{array}$ & $\begin{array}{c}43 \\
(8.6 \%)\end{array}$ & 0.005 & 6.5 & 0.6 & 7.9 & $<0.001$ \\
\hline No symptoms & $\begin{array}{c}26 \\
(3.2 \%) \\
\end{array}$ & $\begin{array}{c}13 \\
(4.4 \%)\end{array}$ & $\begin{array}{c}13 \\
(2.6 \%) \\
\end{array}$ & 0.160 & $\mathrm{NA}^{2}$ & NA & NA & NA \\
\hline
\end{tabular}

${ }^{1}$ The number of children and adults at the age when the diagnosis of CD was made. Chi-squared test was used for statistical analysis.

${ }^{2} \mathrm{NA}=$ not available.

\subsection{Duration of symptoms before CD diagnosis}

The mean duration of symptoms before $\mathrm{CD}$ diagnosis depended on the particular symptom, and ranged from 4.7 years for diarrhea to 9.2 years for anemia (Table 2). The mean duration of any symptom before establishing the diagnosis was 7.3 years for the whole analyzed group. Symptoms lasted on average significantly longer in adults than in children, respectively 9.0 and 3.1 years $(p<0.001)$. The symptom that lasted for the longest time before $\mathrm{CD}$ diagnosis in adults was anemia (11.6 years on average), whereas in children it was depression (4.1 years on average). It is worth mentioning that depression was a rare symptom in the pediatric group (only $5.8 \%$ ). Among adults, the symptom that lasted for the shortest period prior to CD diagnosis was diarrhea (5.8 years on av- 
erage) and in children the symptom that lasted for the shortest period prior to CD diagnosis was osteoporosis (0.6 years on average).

\subsection{The effect of GFD on CD symptoms}

The respondents were asked about GFD adherence after CD diagnosis. Almost all children $(98.7 \%)$ claimed to follow GFD all of the time. The percentage of adults who reported adhering to a GFD at all times was significantly lower in comparison with children $(91.9 \%, \mathrm{p}<0.001)$. Adherence to GFD most of the time was reported by 46 respondents (5.7\%): 2 children $(0.9 \%)$ and $44(7.7 \%)$ adults $(\mathrm{p}<0.001)$. One child admitted to not following a GFD, whereas two adults reported to eat gluten-free products rarely.

In spite of CD diagnosis and subsequent adherence to a GFD, symptoms of CD persisted (Table 3). The most frequent symptoms after CD diagnosis among all patients were: flatulence $(41.8 \%)$, abdominal pain $(39.0 \%)$, chronic fatigue $(34.9 \%)$ and headache (28.2\%). No symptoms were reported by 155 (19.4\%) of all CD patients, a percentage that was significantly higher in children than in adults $(29.3 \%$ versus $15.6 \%, \mathrm{p}<0.001)$. Among children, the most common symptoms which persisted despite GFD diet were: abdominal pain $(37.0 \%)$, flatulence $(31.6 \%)$, headache $(20.0 \%)$, chronic fatigue $(19.3 \%)$ and skin rash (19.3\%). The most frequent symptoms among adults after CD diagnosis were: flatulence $(47.8 \%)$, chronic fatigue $(44.0 \%)$, abdominal pain $(40.2 \%)$ and headache $(33.0 \%)$. The symptom that lasted for the longest time in children after the diagnosis was headache (5.5 years), while in adults it was weight loss (6.4 years). The mean duration of symptoms after diagnosis in both age group was similar, except for anemia (1.4 years in children and 3.6 years in adults, $\mathrm{p}=0.001$ ).

Table 3. Incidence and the mean duration of symptoms after $C D$ diagnosis in pediatric and adult patients.

\begin{tabular}{|c|c|c|c|c|c|c|c|c|}
\hline \multirow[b]{2}{*}{ Symptoms } & \multicolumn{4}{|c|}{$\begin{array}{l}\text { Number and percentage of patients reporting each } \\
\text { symptom }\end{array}$} & \multicolumn{4}{|c|}{ Mean duration in years after CD diagnosis } \\
\hline & \begin{tabular}{l}
\multicolumn{1}{c}{ All } \\
patients \\
$(\mathrm{n}=796)$
\end{tabular} & $\begin{array}{l}\text { Children } \\
(\mathrm{n}=294)^{1}\end{array}$ & $\begin{array}{l}\text { Adults } \\
(\mathrm{n}=502)^{1}\end{array}$ & $\mathrm{p}$ & $\begin{array}{c}\text { All } \\
\text { patients } \\
(\mathrm{n}=796)\end{array}$ & $\begin{array}{l}\text { Children } \\
(\mathrm{n}=294)^{1}\end{array}$ & $\begin{array}{l}\text { Adults } \\
(\mathrm{n}=502)^{1}\end{array}$ & $\mathrm{p}$ \\
\hline Flatulence & $\begin{array}{c}333 \\
(41.8 \%)\end{array}$ & $\begin{array}{c}93 \\
(31.6 \%)\end{array}$ & $\begin{array}{c}240 \\
(47.8 \%)\end{array}$ & $<0.001$ & 3.7 & 2.7 & 4.1 & 0.055 \\
\hline $\begin{array}{l}\text { Abdominal } \\
\text { pain/Bloating }\end{array}$ & $\begin{array}{c}311 \\
(39.0 \%)\end{array}$ & $\begin{array}{c}109 \\
(37.0 \%)\end{array}$ & $\begin{array}{c}202 \\
(40.2 \%)\end{array}$ & 0.377 & 2.1 & 2.0 & 2.2 & 0.719 \\
\hline Chronic fatigue & $\begin{array}{c}278 \\
(34.9 \%)\end{array}$ & $\begin{array}{c}57 \\
(19.3 \%)\end{array}$ & $\begin{array}{c}221 \\
(44.0 \%)\end{array}$ & $<0.001$ & 2.7 & 2.5 & 2.8 & 0.656 \\
\hline Anaemia & $\begin{array}{c}214 \\
(26.8 \%)\end{array}$ & $\begin{array}{c}5 \\
(1.7 \%)\end{array}$ & $\begin{array}{c}161 \\
(32.0 \%)\end{array}$ & $<0.001$ & 3.0 & 1.4 & 3.6 & 0.001 \\
\hline Diarrhoea & $\begin{array}{c}203 \\
(25.5 \%)\end{array}$ & $\begin{array}{c}54 \\
(18.3 \%)\end{array}$ & $\begin{array}{c}149 \\
(29.6 \%)\end{array}$ & $<0.001$ & 1.6 & 1.5 & 1.6 & 0.876 \\
\hline Headache & $\begin{array}{c}225 \\
(28.2 \%)\end{array}$ & $\begin{array}{c}59 \\
(20.0 \%)\end{array}$ & $\begin{array}{c}166 \\
(33.0 \%)\end{array}$ & $<0.001$ & 4.7 & 5.5 & 4.4 & 0.363 \\
\hline Weight loss & $\begin{array}{c}129 \\
(16.2 \%)\end{array}$ & $\begin{array}{c}36 \\
(12.2 \%)\end{array}$ & $\begin{array}{c}93 \\
(18.5 \%)\end{array}$ & 0.020 & 2.4 & 3.0 & 6.4 & 0.260 \\
\hline Skin rash & $\begin{array}{c}176 \\
(22.1 \%)\end{array}$ & $\begin{array}{c}57 \\
(19.3 \%)\end{array}$ & $\begin{array}{c}119 \\
(23.7 \%)\end{array}$ & 0.157 & 2.9 & 2.8 & 2.9 & 0.871 \\
\hline Joint pains & $\begin{array}{c}181 \\
(22.7 \%)\end{array}$ & $\begin{array}{c}43 \\
(14.6 \%)\end{array}$ & $\begin{array}{c}138 \\
(27.4 \%)\end{array}$ & $<0.001$ & 3.6 & 4.6 & 3.3 & 0.244 \\
\hline Constipation & $\begin{array}{c}185 \\
(23.2 \%)\end{array}$ & $\begin{array}{c}53 \\
(18.0 \%)\end{array}$ & $\begin{array}{c}132 \\
(26.2 \%)\end{array}$ & 0.008 & 2.7 & 1.8 & 3.0 & 0.256 \\
\hline
\end{tabular}




\begin{tabular}{|c|c|c|c|c|c|c|c|c|}
\hline Mouth ulcer & $\begin{array}{c}117 \\
(14.6 \%)\end{array}$ & $\begin{array}{c}27 \\
(9.1 \%)\end{array}$ & $\begin{array}{c}90 \\
(17.9 \%)\end{array}$ & 0.001 & 2.3 & 2.1 & 2.4 & 0.759 \\
\hline Depression & $\begin{array}{c}90 \\
(11.3 \%)\end{array}$ & $\begin{array}{c}21 \\
(7.1 \%)\end{array}$ & $\begin{array}{c}69 \\
(13.7 \%)\end{array}$ & 0.005 & 3.1 & 3.2 & 3.1 & 0.916 \\
\hline Ataxia & $\begin{array}{c}32 \\
(4.0 \%)\end{array}$ & $\begin{array}{c}11 \\
(3.7 \%)\end{array}$ & $\begin{array}{c}21 \\
(4.1 \%)\end{array}$ & 0.759 & 3.0 & 4.2 & 2.4 & 0.336 \\
\hline Osteoporosis & $\begin{array}{c}46 \\
(5.7 \%)\end{array}$ & $\begin{array}{c}8 \\
(2.7 \%)\end{array}$ & $\begin{array}{c}38 \\
(7.5 \%)\end{array}$ & 0.005 & 5.2 & 1.3 & 6.0 & 0.163 \\
\hline No symptoms & $\begin{array}{c}155 \\
(19.4 \%)\end{array}$ & $\begin{array}{c}80 \\
(27.2 \%)\end{array}$ & $\begin{array}{c}75 \\
(14.9 \%) \\
\end{array}$ & $<0.001$ & - & - & - & - \\
\hline
\end{tabular}

${ }^{1}$ The number of children and adults at the age when diagnosis was made. Chi-squared test was used for statistical analysis.

\subsection{Comorbidity}

The coexistence of comorbid conditions known to be associated with CD was also assessed (Table 4). Thyroid diseases $(23.4 \%)$, depression (12.6\%), immunoglobulin A (IgA) deficiency $(10.7 \%)$ and miscarriages $(9.4 \%)$ were the most frequently reported comorbid disorders in the whole study group. Adults reported slightly but significantly higher ( $\mathrm{p}<0.001$ ) occurrence of comorbid medical condition $(88.3 \%)$ compared to the pediatric group $(70.2 \%)$. The most common comorbid disease in adults were thyroid diseases $(28.8 \%)$, which occurred almost 3 times more often than in children $(9.8 \%$, $\mathrm{p}<0.001)$. In children IgA deficiency was the most common comorbidity $(13.3 \%)$, and there was no significant difference in occurrence of IgA deficiency between children and adults $(13.3 \%$ versus $9.6 \%)$. Many adult patients $(42.7 \%)$ reported having other diseases than those specified in the questionnaire, such as epilepsy, peptic ulcer disease, colitis ulcerosa, Crohn's disease, irritable bowel syndrome, ischemic hearth disease, hypertension, gastroesophageal reflux, psoriasis, endometriosis, albinism, and allergic diseases (food and pollen allergy, atopic dermatitis, bronchial asthma). Children (34.2\%) also claimed to have other diseases than those specified in the questionnaire, such as gastroesophageal reflux, peptic ulcer disease and allergy (atopic dermatitis, food and pollen allergy, bronchial asthma).

Table 4. The prevalence of comorbid diseases among children and adults with diagnosed CD.

\begin{tabular}{ccccc}
\hline Comorbid diseases & $\begin{array}{c}\text { All respondents } \\
\text { (n=796) }\end{array}$ & $\begin{array}{c}\text { Children } \\
(\mathbf{n = 2 2 4})\end{array}$ & $\begin{array}{c}\text { Adults } \\
(\mathbf{n = 5 7 2 )}\end{array}$ & $\mathbf{p}$ \\
\hline Thyroid diseases & $23.4 \%$ & $9.8 \%$ & $28.8 \%$ & $<0.001$ \\
Depression & $12.6 \%$ & $2.2 \%$ & $16.7 \%$ & $<0.001$ \\
IgA deficiency & $10.7 \%$ & $13.3 \%$ & $9.6 \%$ & 0.128 \\
Miscarriages & $9.4 \%$ & $0.0 \%$ & $13.2 \%$ & $<0.001$ \\
Liver diseases & $4.2 \%$ & $0.9 \%$ & $5.4 \%$ & 0.004 \\
Infertility & $4.2 \%$ & $0.0 \%$ & $5.4 \%$ & 0.004 \\
Type 1 diabetes mellitus & $3.5 \%$ & $5.3 \%$ & $2.8 \%$ & 0.082 \\
Oncological diseases & $1.9 \%$ & $0.0 \%$ & $2.6 \%$ & 0.014 \\
Genetic syndrome & $1.1 \%$ & $3.1 \%$ & $0.4 \%$ & 0.001 \\
Attention-deficit hyperactivity & $1.0 \%$ & $2.2 \%$ & $0.5 \%$ & 0.031 \\
disorder & $0.6 \%$ & $0.0 \%$ & $0.9 \%$ & 0.159 \\
Myocardial infarction & $0.4 \%$ & $0.0 \%$ & $0.5 \%$ & 0.276 \\
Stroke & & & & \\
\hline
\end{tabular}




\begin{tabular}{ccccc}
\hline Other diseases $^{2}$ & $40.3 \%$ & $34.2 \%$ & $42.7 \%$ & 0.028 \\
No comorbid disease & $16.8 \%$ & $29.8 \%$ & $11.7 \%$ & $<0.001$ \\
\hline
\end{tabular}

${ }^{1}$ IgA - immunoglobulin A

${ }^{2}$ Other diseases reported by the respondents were: atopic dermatitis, albinism, bronchial asthma, food and pollen allergy, colitis ulcerosa, Crohn's disease, endometriosis, epilepsy, ischaemic hearth disease, irritable bowel syndrome, hypertension, gastroesophageal reflux, psoriasis.

\subsection{Diagnostic process}

Almost all children had undergone serological tests $(n=270,91.8 \%$ of all children included to the study). Out of all children, $67(22.8 \%)$ were diagnosed without duodenal biopsy: 23 children before the year 2012 and 44 children after the year 2012. HLA-typing was performed in $117(39.7 \%)$ children and in $94(18.7 \%, \mathrm{p}=0.0001)$ adults (Table 5). Among celiac adults, most (83.2\%) had undergone duodenal biopsy, and serological tests were performed at significantly lower frequency than in children: $79.0 \%$ and $91.8 \%$ respectively $(\mathrm{p}=0.0001)$.

Table 5. Diagnostic tools used for CD diagnosis.

\begin{tabular}{ccccc}
\hline & $\begin{array}{c}\text { All respondents } \\
(\mathbf{n = 7 9 6 )}\end{array}$ & $\begin{array}{c}\text { Children } \\
(\mathbf{n = 2 9 4})^{\mathbf{1}}\end{array}$ & $\begin{array}{c}\text { Adults } \\
(\mathbf{n = 5 0 2})^{\mathbf{1}}\end{array}$ & p \\
\hline Serological tests & $667(83.7 \%)$ & $270(91.8 \%)$ & $397(79.0 \%)$ & 0.0001 \\
Duodenal biopsy & $645(81.0 \%)$ & $227(77.2 \%)$ & $418(83.2 \%)$ & 0.0394 \\
Genetic tests (HLA-typing) & $211(26.5 \%)$ & $117(39.7 \%)$ & $94(18.7 \%)$ & 0.0001 \\
\hline
\end{tabular}

I1 The number of children and adults at the age when CD diagnosis was made. Fisher exact test was used for statistical analysis.

We also asked questions about the number of appointments with General Practitioners (GPs) due to symptoms which occurred prior to CD diagnosis, and this information was provided by 792 (99.5\%) respondents. The average number of appointments with GPs was 17.7. Analysis using the Spearman's rank correlation coefficient showed a statistically significant relationship between the number of visits and the mean duration of all symptoms $(\mathrm{p}<0.001)$. The longer the symptoms lasted, the greater the number of visits (Table 6). There was no statistically significant difference between children and adults regarding the number of appointments with GPs due to symptoms prior to $C D$ diagnosis.

Table 6. Mean number of appointments with GPs ${ }^{1}$ prior to CD diagnosis about the symptoms, by duration of symptoms.

Duration of symptoms before the diagnosis in years
All patients $(n=796)$

Children $(\mathrm{n}=224)$

Adults ( $=572)$

\section{Number of} appointments
Mean

\begin{abstract}
Number of
appointments
\end{abstract}

Mean

Number of $\quad$ Mean
appointments




\begin{tabular}{|c|c|c|c|c|c|c|}
\hline$<1$ & 94 & 7.6 & 63 & 9.0 & 31 & 4.7 \\
\hline $1-5$ & 367 & 13.5 & 189 & 15.9 & 178 & 11.0 \\
\hline $5-10$ & 164 & 20.2 & 31 & 19.8 & 133 & 20.3 \\
\hline $10-20$ & 124 & 28.0 & 9 & 20.7 & 115 & 28.5 \\
\hline$>20$ & 43 & 36.5 & 0 & - & 43 & 36.5 \\
\hline In total & $792^{2}$ & 17.7 & 293 & 15.2 & 500 & 19.3 \\
\hline & $\begin{array}{r}{ }^{1} \mathrm{G} \\
{ }^{2} \mathrm{~S} \\
\text { did not } \\
\text { number }\end{array}$ & $\begin{array}{l}\text { ral Pro } \\
\text { s and } \\
\text { ata on } \\
\text { tment }\end{array}$ & $\begin{array}{l}\text { not } \\
\text { of sy } \\
\text { hetic } 1\end{array}$ & $\begin{array}{l}\text { a on th } \\
\text { ior to }\end{array}$ & $\begin{array}{l}\text { of ap } \\
\text { Resu }\end{array}$ & $\begin{array}{l}\text { vith } \\
\text { ted a }\end{array}$ \\
\hline
\end{tabular}

\section{Discussion}

It has been proved that more and more patients with $\mathrm{CD}$ lack gastrointestinal symptoms, which are present in classical CD $[3,11]$. In spite of increasing prevalence of nonclassical CD manifestation, our analysis showed that gastrointestinal symptoms remain the most frequent CD manifestation among Polish patients [12]. Abdominal pain, flatulence and diarrhea were the most common CD symptoms among children, and these results are in line with an American analysis reporting that $82 \%$ of children diagnosed with $C D$ had a gastrointestinal manifestation [13]. We found that in adults the clinical picture was more varied than in children, and although gastrointestinal symptoms were very common (flatulence and abdominal pain were observed in $62 \%$ and $68 \%$, respectively), fatigue was the most common symptom (75\%). Anemia was also seen among the most common symptoms in both children and adults. Interestingly, some gastrointestinal symptoms such as diarrhea, constipation, and flatulence were significantly more often present in adults than in children. The most common extraintestinal symptoms reported by Polish children were chronic fatigue and skin rash. In comparison, Jericho et al. found that short stature (33\%), fatigue (28\%), and headache $(20 \%)$ were the most common extraintestinal symptoms in CD children. The same authors have shown that iron deficiency anemia ( $48 \%)$, fatigue $(37 \%)$, and headache/psychiatric disorders $(24 \%)$ were common in adults [12].

Undoubtedly, heterogenous clinical manifestation of CD contributes to the delay in the diagnosis. As CD symptoms are not specific, they remain unrecognized as $\mathrm{CD}$ and represent a challenge for clinicians [4].

Regardless of the age, Polish patients waited slightly longer than 7 years on average for a $\mathrm{CD}$ diagnosis to be established. The symptom that lasted for the longest time in the analyzed group prior to $\mathrm{CD}$ diagnosis was anemia (more than 9 years). There were also other symptoms that lasted more than 7 years: headache, constipation, flatulence, joint pains, skin rash, mouth ulcer and bloating $(8.6 ; 8.5 ; 8.1 ; 7.6 ; 7.4 ; 7.2$ and 7.1 years, respectively). In addition, our analysis showed that adults waited significantly longer for the proper diagnosis than children (9 years versus 3.1 years). Similar results were reported by Vavricka et al, regarding CD patients in Switzerland [11]. They found that total di- 
agnostic delay was significantly higher in patients over 30 years of age at diagnosis. In other countries, the delay in CD diagnosis ranged from 9 to 13 years [4], but it is worth mentioning that these studies were performed in the years 2001-2012, so the time shift between them and our study could affect the results.

Our results show that CD diagnosis still is a problem in Poland, especially in adult patients. We found that most adults (83.2\%) underwent duodenal biopsy, and serological tests were done only in almost $80 \%$ of them. In contrast, serological tests were done in almost all pediatric patients $(91.8 \%)$, and CD diagnosis without duodenal biopsy was performed in $22.8 \%$ of them. These differences result from the current diagnostic recommendations for CD. Whereas according the ESPGHAN guidelines CD in children starting from 2012 can be recognized without intestinal biopsy [14, 15], in adults the histopathological analysis of duodenal specimens is still a gold standard [14,16]. We suggest that diagnostic problems in adults can be associated with non-specific varied clinical picture, but also with a diagnostic approach based on the histopathological assessment. A recent study performed in the United Kingdom revealed that the majority of endoscopists did not follow guidelines for diagnostic endoscopy for CD, which led to a reduction in diagnosis rates by over $50 \%$ [17]. In addition, the longer diagnostic delay observed in adults might result from the fact that in Poland CD has been regarded as a pediatric disease until quite recently [9]. The Polish manual "Internal diseases: a manual for medical students", edited by Franciszek Kokot and issued in 1991, states that "Since celiac disease is a pediatric disorder, it will not be presented in detail in this manual" [18]. The description of CD in the 6th issue of the same book, published in 1996, was not expanded: "(CD) disease will not be presented in this book since it is a pediatric disorder" [19]. This signifies that in Poland in the 1990s, CD was still considered as a pediatric disease, which would be consistent with the pattern of diagnosis reported in this study.

It has been proved that even a short delay in CD diagnosis results in increased health burden at the individual as well as at society level [4]. Our analysis revealed that celiac patients, in whom symptoms lasted longer prior to diagnosis, made more appointments with GPs. We also found a correlation between the duration of the diagnostic process, the number of coexistent medical conditions and the duration of CD symptoms prior to diagnosis. Results from a Finnish study were similar to ours: patients who experienced a delay in CD diagnosis of longer than 3 years made more primary health care visits and reported more days of sickness [4]. The Finnish authors also reported an increment in use of antidepressants, analgesics and medicines for dyspepsia in the delayed diagnosis group, which was not analyzed in our study.

Up to date, a GFD is the only known and effective treatment for CD [20]. We showed that although almost all CD patients admitted to strict adherence to a GFD, they still had CD symptoms that lasted for 2.6 years on average after the diagnosis. It was observed that among celiac pediatric patients, symptoms receded earlier after eliminating gluten than in celiac adults, regarding almost all analyzed symptoms, except for headache, joint pain, depression and ataxia. Nevertheless, a statistically significant difference in duration of symptoms after CD diagnosis was observed only in case of anemia.

Strict adherence to GFD imposes numerous restrictions on the patient, having both financial and social implications [21]. What is more, complete elimination of gluten from the diet does not guarantee complete mucosal recovery [22]. What could also contribute to persistent inflammation in bowel mucosa is cross-contamination of gluten-free products with wheat, barley and rye [23]. This might explain why CD symptoms are still present in patients who report adherence to GFD. The levels of antibodies against tissue transglutaminase type 2 , both in children and in adults, may normalize after a year since the introduction of GFD [24], which means that the disease is still active. 
Comorbidity in CD has been widely discussed and a correlation between the prevalence of CD and some genetic disorders, e. g. Down syndrome, Turner syndrome, Williams syndrome, and IgA deficiency was established [25]. In Polish CD patients, comorbidities were significantly more frequent in adults than in children (respectively, more than $88 \%$ in comparison to $70 \%, \mathrm{p}<0.001$ ). A meta-analysis performed in 2016 showed that the prevalence of thyroid diseases in children with CD was higher than in adults with CD (more than 6\% compared to less than 3\%) [16]. In contrast to these findings, thyroid diseases were the most common coexistent disease in Polish CD adults (almost $30 \%$ ) but less prevalent in Polish pediatric CD patients (almost 10\%). Regardless of the numbers, a strong correlation between $\mathrm{CD}$ and autoimmune thyroid diseases was proved and ESPGHAN Guidelines recommend performing serological screening for CD in children with thyroid diseases [14]. The most common concurrent disease among Polish children with CD was IgA deficiency, affecting more than $13 \%$ of underage patients. The frequent coexistence of IgA deficiency and CD (about 10\% of CD patients) explains why serological screening of patients should be started with determination of IgA against tissue transglutaminase type 2 and total IgA [26]. ESPGHAN Guidelines also suggest screening children with type 1 diabetes mellitus for $C D$, as they are known to be at greater risk for CD [14]. The common coexistence of CD and type 1 diabetes mellitus in Polish children (more than 5\%) was also observed.

Patients with CD compared to healthy individuals, more frequently demonstrate concurrent autoimmune diseases (about 5\%) [27]. One possible explanation of this phenomenon is the fact that some autoimmune disorders share genetic background [28]. Another factor that may promote the development of other autoimmune diseases in CD patients is the time of exposure to gluten. In 1999, Ventura et al. revealed that delayed CD diagnosis, and consequently longer exposure to gluten, was associated with higher prevalence of autoimmune diseases [29]. The role of gluten in development of autoimmunity was also shown in a study performed by Cosnes et al. [30]. However, some authors have found no association between delayed CD diagnosis, longer exposure to gluten and development of autoimmune disorders [31]. Our analysis revealed that there was the association between the age at CD diagnosis $(p<0.001)$, the number of comorbid autoimmune disorders ( $\mathrm{p}<0.001)$, and a mean duration of CD symptoms prior to CD diagnosis.

\section{Limitations of the study}

We are conscious of the limitations of the study. First, a response bias cannot be excluded due to the retrospective character of the assessment. As there are no large long-term prospective studies with frequent data collection, retrospective analysis is inevitable. It is worth highlighting that the retrospective method has been widely used in studies on CD and on other diseases [32-34]. Furthermore, it cannot be excluded that the patients are somehow unrepresentative of the entire group of Polish patients with CD. We cannot guarantee that the outcomes of an analogous prospective study would be similar. However, there are limited data on CD epidemiology in Poland to compare with our results.

\section{Conclusions}

Our results demonstrate that the CD diagnostic process still is a problem in Poland, although the mean duration of symptoms prior to CD diagnosis in children was significantly shorter than in adults (3.1 years and 9 years, respectively). Almost all CD patients claimed to be strictly avoiding gluten, but after the introduction of GFD symptoms were still present in the majority of the respondents, with significantly higher frequency in adults than in children. Our results suggest that clinicians should be more aware of the diversity in $\mathrm{CD}$ presentation as one way of improving the diagnostic process, especially 
in adults, and that more could be done to help those diagnosed with CD to adhere to a fully GFD.

\begin{abstract}
Author Contributions: Conceptualization E.M. and A.G.; methodology E.M.; M.C.; B.C.; software E.M.; M.C.; validation E.M.; M.C.; A.G.; B.C; formal analysis E.M.; M.C.; B.C; investigation E.M.; M.C. B.C; resources E.M.; data curation E.M.; M.C.; writing-original draft preparation E.M.; A.G.; B.C.; writing - review and editing E.M.; B.C.; M.W.; A.G; visualization E.M.; M.C.; supervision B.C; A.G.; project administration E.M.; funding acquisition E.M.; All authors have read and agreed to the published version of the manuscript..
\end{abstract}

Funding: The study was a part of internal scientific project financed by the Children's Memorial Health Institute (S147/2016, principal investigator Bożena Cukrowska). The Polish-Ukrainian Foundation of Medicine Development provided financial resources for printing and sending the questionnaires. Surveys with original UK questionnaires conducted by Alaister Gray was partially funded by the National Institute for Health Research Oxford Biomedical Research Center.

Institutional Review Board Statement: The study was conducted according to the guidelines of the Declaration of Helsinki, and approved by The Bioethics Committee of the Children's Memorial Health Institute ((No. 48 /KBE/2017)."

Informed Consent Statement: Informed consent was obtained from all subjects involved in the study. If a participant was less than 16 years old, their parents or guardians gave written consent for them to participate.

Data Availability Statement: The datasets generated and/or analyzed during the current study are not publicly available because they are also being used for further ongoing analyses, but are available from the corresponding author on reasonable request.

Acknowledgments: We would like to thank the Polish Coeliac Society for distribution of questionnaires among its members. We also want to express our gratitude to the Polish CD patients who take part in this study.

Conflicts of Interest: The authors declare no conflict of interest. The funders had no role in the design of the study; in the collection, analyses, or interpretation of data; in the writing of the manuscript, or in the decision to publish the results.

\title{
References
}

1. Singh, P., Arora, A., Strand, T.A., et al., Global Prevalence of Celiac Disease: Systematic Review and Meta-analysis. Clin Gastroenterol Hepatol, 2018. 16(6): p. 823-836 e2.

2. Bai, J.C., Fried, M., Corazza, G.R., et al., World Gastroenterology Organisation global guidelines on celiac disease. J Clin Gastroenterol, 2013. 47(2): p. 121-6.

3. Pelkowski, T.D.,Viera, A.J., Celiac disease: diagnosis and management. Am Fam Physician, 2014. 89(2): p. 99-105.

4. Fuchs, V., Kurppa, K., Huhtala, H., et al., Delayed celiac disease diagnosis predisposes to reduced quality of life and incremental use of health care services and medicines: A prospective nationwide study. United European Gastroenterol J, 2018. 6(4): p. 567-575.

5. Parzanese, I., Qehajaj, D., Patrinicola, F., et al., Celiac disease: From pathophysiology to treatment. World J Gastrointest Pathophysiol, 2017. 8(2): p. 27-38.

6. Mooney, P.D., Evans, K.E., Singh, S., et al., Treatment failure in coeliac disease: a practical guide to investigation and treatment of non-responsive and refractory coeliac disease. J Gastrointestin Liver Dis, 2012. 21(2): p. 197-203.

7. Caio, G., Volta, U., Sapone, A., et al., Celiac disease: a comprehensive current review. BMC Med, 2019. 17(1): p. 142.

8. Majsiak, E., Choina, M., Cukrowska, B., The knowledge of medical professions on celiac disease in opinion of Polish patients with celiac disease. Abstract \#: ICDS00123 Final poster ID: P2-15 on International Coeliac Disease Symposium (ICDS) September 5-7, 2019, Paris, France, 2019.

9. Majsiak, E., Choina, M., Golicki, D., et al., The impact of symptoms on quality of life before and after diagnosis of coeliac disease: the results from a Polish population survey and comparison with the results from the United Kingdom. BMC Gastroenterol, 2021. 21(1): p. 99.

10. Gray, A.M.,Papanicolas, I.N., Impact of symptoms on quality of life before and after diagnosis of coeliac disease: results from a UK population survey. BMC Health Serv Res, 2010. 10: p. 105.

11. Vavricka, S.R., Vadasz, N., Stotz, M., et al., Celiac disease diagnosis still significantly delayed - Doctor's but not patients' delay responsive for the increased total delay in women. Dig Liver Dis, 2016. 48(10): p. 1148-54. 
12. Trovato, C.M., Raucci, U., Valitutti, F., et al., Neuropsychiatric manifestations in celiac disease. Epilepsy Behav, 2019. 99: p. 106393.

13. Jericho, H., Sansotta, N.,Guandalini, S., Extraintestinal Manifestations of Celiac Disease: Effectiveness of the Gluten-Free Diet. J Pediatr Gastroenterol Nutr, 2017. 65(1): p. 75-79.

14. Husby, S., Koletzko, S., Korponay-Szabó, I., et al., European Society for Pediatric Gastroenterology, Hepatology, and Nutrition Guidelines for the Diagnosis of Coeliac Disease. JPGN, 2012. 54(1): p. 136-160.

15. Husby, S., Koletzko, S., Korponay-Szabo, I., et al., European Society Paediatric Gastroenterology, Hepatology and Nutrition Guidelines for Diagnosing Coeliac Disease 2020. J Pediatr Gastroenterol Nutr, 2020. 70(1): p. 141-156.

16. Roy, A., Laszkowska, M., Sundstrom, J., et al., Prevalence of celiac disease in patients with autoimmune thyroid disease - a meta-analysis. Thyroid, 2016.

17. Taylor, M., Blanshard, R., Naylor, G., et al., Do gastroenterologists have medical inertia towards coeliac disease? A UK multicentre secondary care study. BMJ Open Gastroenterology, 2021. 8: p. e000544.

18. Choroby wewnętrzne: podręcznik dla studentów. red. Kokot F. wyd. V, 1991 p. 220.

19. Choroby wewnętrzne: podręcznik dla studentów. red. Kokot F. wyd. VI, 1996.

20. Choung, R.S., Lamba, A., Marietta, E.V., et al., Effect of a Gluten-free Diet on Quality of Life in Patients With Nonclassical Versus Classical Presentations of Celiac Disease. Journal of Clinical Gastroenterology, 2020. 54(7): p. 620-625.

21. Lerner, A.,Matthias, T., Gluten-free Diet - Tough Alley in Torrid Time. International Journal of Celiac Disease, $2017.5:$ p. 50-55.

22. Lerner, A., O'Bryan, T.,Matthias, T., Navigating the Gluten-Free Boom: The Dark Side of Gluten Free Diet. Front Pediatr, 2019. 7: p. 414.

23. Aaron, L.,Torsten, M., Gluten-free Diet - Tough Alley in Torrid Time. International Journal of Celiac Disease, 2017. 5(2): p. 50-55.

24. Midhagen, G., Åberg, A.K., Olcén, P., et al., Antibody levels in adult patients with coeliac disease during gluten-free diet: a rapid initial decrease of clinical importance. Journal of Internal Medicine, 2004. 256(6): p. 519-524.

25. McAllister, B.P., Williams, E.,Clarke, K., A Comprehensive Review of Celiac Disease/Gluten-Sensitive Enteropathies. Clin Rev Allergy Immunol, 2019. 57(2): p. 226-243.

26. Husby, S., Murray, J.A.,Katzka, D.A., AGA Clinical Practice Update on Diagnosis and Monitoring of Celiac Disease-Changing Utility of Serology and Histologic Measures: Expert Review. Gastroenterology, 2019. 156(4): p. 885-889.

27. Lundin, K.E.,Wijmenga, C., Coeliac disease and autoimmune disease-genetic overlap and screening. Nat Rev Gastroenterol Hepatol, 2015. 12(9): p. 507-15.

28. Singh, K., Chang, C.,Gershwin, M.E., IgA deficiency and autoimmunity. Autoimmun Rev, 2014. 13(2): p. $163-77$.

29. Ventura, A., Magazzù, G.,Greco, L., Duration of exposure to gluten and risk for autoimmune disorders in patients with celiac disease. SIGEP Study Group for Autoimmune Disorders in Celiac Disease. Gastroenterology, 1999. 117(2): p. $297-303$.

30. Cosnes, J., Cellier, C., Viola, S., et al., Incidence of autoimmune diseases in celiac disease: protective effect of the gluten-free diet. Clin Gastroenterol Hepatol, 2008. 6(7): p. 753-8.

31. Sategna Guidetti, C., Solerio, E., Scaglione, N., et al., Duration of gluten exposure in adult coeliac disease does not correlate with the risk for autoimmune disorders. Gut, 2001. 49(4): p. 502-5.

32. Eudy, A.M., McDaniel, G.,Clowse, M.E.B., Pregnancy in rheumatoid arthritis: a retrospective study. Clinical Rheumatology, 2018. 37(3): p. 789-794.

33. Fuchs, V., Kurppa, K., Huhtala, H., et al., Factors associated with long diagnostic delay in celiac disease. Scand J Gastroenterol, 2014. 49(11): p. 1304-10.

34. Norström, F., Lindholm, L., Sandström, O., et al., Delay to celiac disease diagnosis and its implications for health-related quality of life. BMC Gastroenterol, 2011. 11: p. 118. 